\title{
Yacon Product (PBY) Modulates Intestinal Constipation and Protects the Integrity of Crypts in Wistar Rats
}

\author{
Mônica de Souza Lima Sant'Anna1*, Vivian Carolina Rodrigues², Tatiane Ferreira Araújo3, \\ Tânia Toledo de Oliveira4, Maria do Carmo Gouveia Pelúzio5, \\ Célia Lúcia de Luces Fortes Ferreira²
}

\author{
${ }^{1}$ Nutrition Course. Federal University of Rio de Janeiro, Campus Macaé, Macaé, Brazil \\ ${ }^{2}$ Department of Food Technology, Federal University of Viçosa, Viçosa, Brazil \\ ${ }^{3}$ Nutrition Course, Pitagoras College, Ipatinga, Brazil \\ ${ }^{4}$ Department of Biochemistry and Molecular Biology, Federal University of Viçosa, Viçosa, Brazil \\ ${ }^{5}$ Departament of Nutrition and Health, Federal University of Viçosa, Viçosa, Brazil \\ Email: ^monicaslsantana@gmail.com
}

How to cite this paper: de Souza Lima Sant'Anna, M., Rodrigues, V.C., Araújo, T.F., de Oliveira, T.T., do Carmo Gouveia Pelúzio, M. and de Luces Fortes Ferreira, C.L. (2018) Yacon Product (PBY) Modulates Intestinal Constipation and Protects the Integrity of Crypts in Wistar Rats. Food and Nutrition Sciences, 9, 1391-1407. https://doi.org/10.4236/fns.2018.912101

Received: November 9, 2018

Accepted: December 25, 2018

Published: December 28, 2018

Copyright $\odot 2018$ by authors and Scientific Research Publishing Inc. This work is licensed under the Creative Commons Attribution International License (CC BY 4.0).

http://creativecommons.org/licenses/by/4.0/

(c) (i) Open Access

\begin{abstract}
This study investigated the use of a product based on yacon (PBY) in microbiological, physical-chemical and intestinal characteristics of Wistar rats arti-

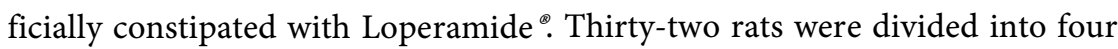
groups: Control (C), Constipated Control (CC), PBY (not constipated) and Constipated PBY (PBYC). The dosage of $0.14 \mathrm{~g}$ of FOS+ inulin/kg was tested. Microbiota, $\mathrm{pH}$ and faeces characteristics of faeces and caecal contents were evaluated. Caecal weight, morphometry of caecal villi and the concentration of short-chain fatty acids were determined. Higher caecal weight was identified in the PBYC animals as well as higher width, height and depth of cripts. The PBY group showed the highest $(\mathrm{p}<0.05)$ concentration of butyrate $(93.2 \pm$ $65.5 \mathrm{mmol} / \mathrm{L}$ ). The supplementation with PBY positively altered the intestine epithelial tissue in constipated animals, keeping the integrity of the caecum crypts.
\end{abstract}

\section{Keywords}

Prebiotic, Yacon, Single Chain Fatty Acid, Constipation

\section{Introduction}

Prebiotics are non-digestible food components that beneficially affect the host due to the selective stimulation of the proliferation and/or the activities of de- 
sirable bacteria population in the colon. This bacterial population is highly active with known biochemical, physiological and immunological effects [1]. Prebiotic targets more frequently the large intestine, although it may have some impact in the microbiota present in the small intestine [2]. This desirable microbiota acts in the production of beneficial metabolites, such as short chain fatty acids (SCFA) [3], antimicrobial substances and immune stimulants [4], manages constipation [5], improves the immune system [6], increases the mineral absorption [7], provides a desirable modulation of the inflammatory response [8], and of the intestinal transit [9].

The soluble dietary fibers fructooligosaccharides (FOS) and the inulin, are of natural occurrence in vegetable products and they are classified as prebiotic due to their low digestibility by mammalian enzymes in the gastrointestinal tract (GIT) [10] [11] and to stimulate growth and/or activity of microorganism with potential human health/well being associations. The only difference between Inulin and FOS is the degree of polymerisation, i.e. the number of individual monosaccharide units that form the molecule. Chemically, they are formed by a specific bond $(\beta 2 \rightarrow 1)$ between a glucose molecule and from two to eight fructose molecules [12] [13]. This type of connection is not broken by digestive enzymes in the gastrointestinal tract. Then, the compounds reach the colon and are fermented by the resident microbiota.

In nature, some foods display traces of FOS, however in low amounts, such as wheat, onion, garlic and banana [14]. Jerusalem artichoke and chicory are the most commercially exploited sources of FOS/inulin, and the isolated compounds are added into food products or marketed as nutraceuticals.

The yacon (Smallanthus sonchifolius) is one of the richest sources of FOS and inulin in nature. Together, these ingredients are equivalent to about $10 \%$ to $14 \%$ of dry matter [15] [16] in this tuberous root which is a tuberous root that belongs to the Asteraceae family and that is originally grown in the Andes. In Brazil, its cultivation began in the 1990s [13] [17]. Since they are a source of FOS and inulin, the roots or their by-products can potentially be used as a source of prebiotics in the diet. The yacon is distinguished by its high water content, which can exceed $90 \%$ (wet weight) [18]. This characteristic makes the root highly perishable. Thus, it is of utmost importance to develop products that can reduce this perishability, enabling this excellent source of prebiotic available throughout the year, since this crop is seasonal.

The consumption of moderate amounts of yacon roots or their products has been shown to be related to the reduction of glicemia [19] [20] and triacylglycerols levels [21], protective effect on experimental colon carcinogenesis [22], increase in the absorption of calcium, and magnesium [7] [23], and to the decreasing symptoms of intestinal constipation [19] [23].

Constipation is a condition characterized by polysymptomatic manifestations that may interfere variously on colonic and anorectal functions. Its prevalence ranges from $15 \%$ to $32 \%$ in the adult population; however, it reaches every age 
group [24] [25] [26]. It is a functional condition and may be a consequence of intestinal dysbiosis. This in balance causes a deficit in the SCFA production, including butyrate, which appears to be connected to the intestinal motility of the intestinal mucosa [27]. Additionally, there may be an increase in moisture stool due to the greater absorption of water and salts [28].

This study evaluated the modulation of constipation in an induced murine model. Wistar rats were induced to the condition with loperamide and treated with a product based on yacon (PBY), a source of the prebiotics FOS and inulin. Microbiological, physicochemical, and morphological variables were analyzed, as well as the characteristics of the caecum.

\section{Material and Methods}

\subsection{Prebiotic (PBY) Composition and Gavage Preparation}

The PBY was processed according to the methodology proposed by Rodrigues, 2011 [20] and application for a patent (PI 1106621-0) has been submitted. The components determined were: moisture content, total carbohydrates, total lipids, ashes, protein (factor for conversion 6.25), according to Association of Official Analytical Chemists, 1997 [29]. Soluble sugars (glucose, sucrose, fructose) and fructans were determined as described by Lobo et al., 2007 (12). The gavage solution of PBY was prepared weekly. To prepare the PBY, the weight of rats from the groups PBY and PBYC was averaged out weekly in order to calculate the gavage solution. From this data it was calculated the amount of FOS and inulin per kilogram body weight and it was calculated the amount of PBY required to provide the daily dose of the prebiotic to be administered. The PBY was diluted in deionized water and this solution was given to the animals daily.

\subsection{Animals and Diets}

Thirty-two male, 45-day-old Wistar rats were obtained from the experimental animal house at the Universidade Federal de Viçosa, Minas Gerais, Brazil). The animals were housed individually in appropriate cages with proper ventilation, 12 hours luminosity cycles (light/dark) and an average temperature of $22^{\circ} \mathrm{C}$. They received Purina $a^{\circledR}$ commercial ration during the whole period of the study and then separated into four groups, as shown in Figure 1.

[Phase I-Induction: lasts 5 days]: Intestinal constipation was induced with loperamide. The compound was resuspended in $0.9 \%$ of sodium chloride, and managed through gavage in two periods of the day ( 8 a.m. and 4 p.m.) during 5 days [30].

[Phase II:-treatment: lasts 28 days]: The amount of administered FOS/inulin (PBY) was based on a study from Genta et al. [19]. The solution containing PBY was administered (gavage) daily at 8 a.m and was calculated on the basis of the weekly average weight of each group, diluted in deionized water. Weight and the food consumption of these the animals were monitored weekly. Weight gain was determined by the difference between final and initial weight and the Coefficient 


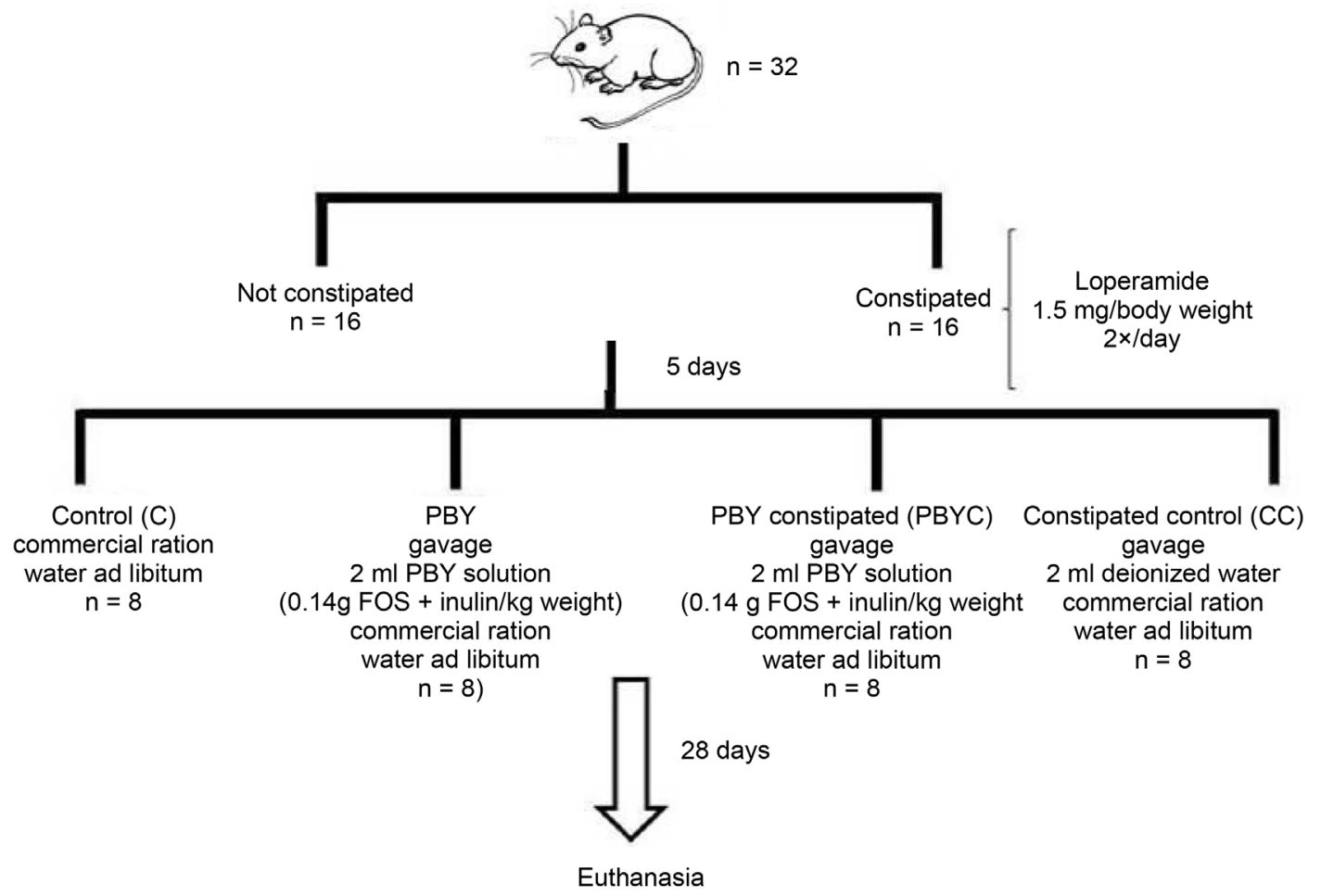

Figure 1. Organization chart of experiment. Fase 1: 5 days, constipation induction. Fase II: 28 days, constipation modulation.

of Alimentary Effectiveness (CEA) was calculated according to the formula: $\mathrm{CEA}=$ (weight gain/total food consumption). Phase II lasted 28 days. The animals were euthanized by $\mathrm{CO}_{2}$ inhalation at the end of the study, after 12 hours of fasting. The caecal content and total faeces were removed and stored in sterile plastic bags at $-80^{\circ} \mathrm{C}$. The organ was then weighed and washed with phosphate buffer (PBS) and fixed through the immersion in 10\% paraformaldehyde in PBS $0.1 \mathrm{M}$, at room temperature, for 24 hours. After this period, the organ was transferred to a solution of absolute ethanol (70\%) for maintenance up to the time of processing for histological analysis. The relative weight (RW) of the caecum was calculated as the ratio between the caecal weight and the weight of the animal.

\subsection{Faecal Score}

This evaluation was done through the visual observation of the faeces, and score determination on a scale 1 to 5 : score 1-hard faeces, dehydrated with small, dry pellets; score 2-hard, dry, firm and well formed faeces; score 3-soft, well formed, humid faeces with its original format; score 4-soft faeces without a format; score 5-liquid faeces [31]. The visual observation was carried out on the last day of constipation induction and on the last PBY consumption day.

\subsection{Microbiological and $\mathrm{pH}$ Analyses}

Microbiological counts $\left(\log _{10} \mathrm{UFC}^{-1}\right)$ were carried out in duplicates, of different 
dilutions, pour plating in selective media: Rogosa agar medium (Difco) for Lactobacillus [32], modified MRS agar (Difco) [33] for Bifidobacterium, RCM agar (Difco) for Clostridium [34]; Wilkins Chalgrens agar (Difco) + garamycin solution [40 mg/400 ml medium] for Bacteroides, Wilkins Chalgrens agar (Difco) for total anaerobics. All samples were incubated at $37^{\circ} \mathrm{C} / 72$ hours in anaerobic jars (Gas Pak Jar, Franklin Lakes, USA) containing $\mathrm{H}_{2}$ and $\mathrm{CO}_{2}$ generators.

Analysis of $\mathrm{pH}$ of caecal content was carried with $\mathrm{pH}$ meter (Bel Engineering-W3B, Monza, Italy). The samples were submitted to decimal dilutions in sterile peptone water, plated in duplicates into different media, incubated as indicated previously.

\subsection{Histological Analysis}

Samples were prepared as indicated previously [35] In short, caecum and large intestine fragments were removed and fixed in formalin. After dehydration in ethanol of increasing gradient, the material was diaphanized in xylol and included in paraffin. Histological slides prepared with $7 \mu \mathrm{m}$ thickness using a rotating microtome (Olympus America Inc. CUT4055), then dyed with hematoxylin and eosin.

The images of these histological slides were captured with an $10 \times$ objective. The following measures were taken with the Pro-Plus ${ }^{\oplus}$ Image Analysis Software system, Version 4.5 (Media Cybernetics):

- Crypt height: ten random fields were chosen per animal. At least 30 villi for each experimental group were measured. Only villi with defined epithelium and visible conjunctives were chosen.

- Crypt width: in the same villi used in the height analysis, the width was measured with the average point of the villi.

- Depth of the crypts: the same villi were measured depth considering that the base and the apex of the crypts were visible.

\subsection{Analysis of Short Chain Fatty Acids}

The analyses of short-chain fatty acids were performed in duplicate, as proposed by Smiric-ktjardes et al. [36]. Standard solutions were made diluting stock solutions of acetic acid, propionic and butyric. Each solution was injected into the chromatograph to obtain the curves correlating peak area to the concentration of acid in the solution. The volume of $1 \mu \mathrm{L}$ of each sample was injected with the aid of syringe $10 \mu \mathrm{L}$ in Splitless system. Each acid present was identified and quantified by comparison with the retention times and concentrations of the fatty acids in the standard solutions. The calculations were made by microcomputer coupled to gas chromatography system equipped with the GC program Solution.

\subsection{Ethics Committee}

The project was approved by the Ethics Committee for Animal Research of the 
Federal University of Viçosa. The study was conducted according to the Ethical Principles in Animal Experimentation adopted by the National Council for Control of Animal Experimentation (CONCEA).

\subsection{Statistical Analysis}

The Kolmogorov-Smirnov test was used to evaluate the distribution of the variable. Based on the test results, either parametric or nonparametric test were performed. Analysis of variance (ANOVA) was chosen for comparisons between three or more independent groups that displayed normal distribution. In situations with any significant difference, the post-hoc Tukey test was carried out in order to identify which groups differed. For the groups that did not present normal distribution, Kruskall-Wallis test and Dunn's post hoc tests were used. The level of rejection of the null hypothesis was $0.05 \%$ or $5 \%$.

For data analyses, the SAS [Statistical Analysis System-SAS Institute Inc., Cary, NC, USA], version 20.9, licensed to UFV, was used.

\section{Results}

\subsection{PBY Composition}

The prebiotic evaluated throughout this study carried in $100 \mathrm{~g}$ the following composition (\%): carbohydrate (29.07); lipid (0.21), protein (0.5); moisture (69.8); ashes (0.42); and oligofructanes [FOS and inulin] (14.54).

\subsection{Faecal Score}

The values of faecal score at the end of the induction phase (5 days) of constipation are shown in Table 1 and that after the treatment period (28 days), Table 2.

The faeces from animals maintained with control diet fall into scores 2 and 3 , while for those not constipated with PBY, the scores were 3 and 4. One animal from the constipated group (CC) not receiving PBY, showed very hard, dry faeces while none from the constipated group receiving PBY had faeces with this

Table 1. Faecal scores in the animals after a 5 day induction of intestinal constipation with loperamide (phase I).

\begin{tabular}{ccc}
\hline \multirow{2}{*}{ Score $^{*}$} & \multicolumn{2}{c}{ No. of animals per group } \\
\cline { 2 - 3 } & Constipated & Non constipated \\
\hline 1 & 14 & 0 \\
2 & 2 & 1 \\
3 & 0 & 1 \\
4 & 0 & 0 \\
5 & 0 & 16 \\
\hline
\end{tabular}

*score 1-hard faeces, dehydrated with small, dry pellets; score 2-hard, dry, firm and well formed faeces; score 3-soft, well formed, humid faeces with its original format; score 4-soft faeces without a format; score 5-liquid faeces [31]. 
Table 2. Faecal score values after 28 days of treatment (phase II).

\begin{tabular}{ccccc}
\hline \multirow{2}{*}{ ccore $^{*}$} & \multicolumn{4}{c}{ Group/no. of animals } \\
\cline { 2 - 5 } & C & CC & PBY & PBYC \\
\hline 1 & 0 & 1 & 0 & 0 \\
2 & 2 & 5 & 0 & 1 \\
3 & 6 & 2 & 5 & 5 \\
4 & 0 & 0 & 3 & 2 \\
5 & 0 & 0 & 0 & 0 \\
Total & 8 & 8 & 8 & 8 \\
\hline
\end{tabular}

Scores* score 1-hard faeces, dehydrated with small, dry pellets; score 2-hard, dry, firm and well formed faeces; score 3-soft, well formed, humid faeces with its original format; score 4-soft faeces without a format; score 5-liquid faeces [31]. Treatments: ${ }^{*} \mathrm{C}$ (not constipated, normal diet); PBY (not constipated, diet with PBY)), CC (constipated, normal diet without PBY) and PBYC (constipated, diet with PBY).

score. Another important observation is that none of the subjects presented score 5 (diarrhea), an undesirable effect.

\subsection{Animal Weight, Weight Gain, Food Consumption, Coefficient of Alimentary Effectiveness (CEA), Faecal and Caecal pH, Caecal Weight and Relative Weight of Caecum}

Data regarding animal weight, weight gain, food consumption, CEA, $\mathrm{pH}$ of faeces and caecal content, and relative weight of caecum are indicated in Table 3.

Animal weight, weight gain, feed intake, CEA and the caecal $\mathrm{pH}$ values were similar among groups $(\mathrm{p}>0.05)$. The total faecal $\mathrm{pH}$ was higher in CC and PBY compared to the control (not constipated group). The caecal weight was lower $(\mathrm{p}<0.05)$ in the PBY group.. The relative weight of the caecum was lower $(\mathrm{p}<$ $0.05)$ in the animals from PBYC than in the groups $\mathrm{C}$ and PBY. The moisture content of feces was higher for the groups that received the PBY.

\subsection{Faeces Bacterial Counts}

The quantification of microbial groups is indicated in Table 4 .

\subsection{Morphometry of Intestinal Villus}

Height, width and depth $[\mu \mathrm{m}]$ of the crypts of the cecum of the animals from different groups after 28 days treatment, are indicated in Table 5.

Comparing the variables in the constipated groups, PBYC measurements are higher $(\mathrm{p}<0.05)$ than $\mathrm{CC}$, indicating the impact of the prebiotic in the protection of caecum epithelium (Figure 2).

\subsection{Short Chain Fatty Acids}

The quantification of short chain fatty acids is indicated in Table 6.

The only difference detect is related to butyric acid. Group PBY presented higher values than the constipated animals without prebiotic treatment (CC). 
Table 3. Animal weight, weight gain, feed intake, Coefficient of Alimentary Effectiveness (CEA), $\mathrm{pH}$ of stool and ceacal contents, ceacal weight, relative weight of the caecum and faeces moisture of Wistar rats after 28 days of intervention.

\begin{tabular}{ccccc}
\hline \multirow{2}{*}{ Variables } & \multicolumn{4}{c}{ Groups } \\
\cline { 2 - 5 } & C & CC & PBY & PBYC \\
\hline Animal weight $[\mathrm{g}]$ & $224.51^{\mathrm{a}} \pm 16.81$ & $220.24^{\mathrm{a}} \pm 10.58$ & $220.43^{\mathrm{a}} \pm 11.81$ & $208.87^{\mathrm{a}} \pm 13.60$ \\
Weight gain (g) & $153.15^{\mathrm{a}} \pm 15.20$ & $151.45^{\mathrm{a}} \pm 13.90$ & $146.37^{\mathrm{a}} \pm 15.78$ & $134.94^{\mathrm{a}} \pm 19.48$ \\
$\begin{array}{c}\text { Food } \\
\text { consumption (g) }\end{array}$ & $148.72^{\mathrm{a}} \pm 10.31$ & $154.00^{\mathrm{a}} \pm 8.76$ & $149.26^{\mathrm{a}} \pm 5.23$ & $144.51^{\mathrm{a}} \pm 11.22$ \\
CEA (\%) & $17.27^{\mathrm{a}} \pm 1.38$ & $16.48^{\mathrm{a}} \pm 1.10$ & $16.42^{\mathrm{a}} \pm 1.46$ & $15.63^{\mathrm{a}} \pm 1.76$ \\
pH total faeces & $5.97^{\mathrm{a}} \pm 0.44$ & $7.12^{\mathrm{b}} \pm 0.42$ & $6.93^{\mathrm{b}} \pm 0.63$ & $6.74^{\mathrm{a}} \pm 0.28$ \\
pH caecal contents & $6.55^{\mathrm{a}} \pm 1.02$ & $6.82^{\mathrm{a}} \pm 1.67$ & $6.54^{\mathrm{a}} \pm 1.10$ & $6.71^{\mathrm{a}} \pm 1.32$ \\
$\begin{array}{c}\text { Caecum weight (g) } \\
\text { Relative weight of } \\
\text { caecum (\%) }\end{array}$ & $1.37^{\mathrm{a}} \pm 0.25$ & $1.26^{\mathrm{ab}} \pm 0.20$ & $1.04^{\mathrm{b}} \pm 0.16$ & $1.42^{\mathrm{a}} \pm 0.24$ \\
$\begin{array}{c}\text { Feces moisture } \\
\text { content (\%) }\end{array}$ & $0.63^{\mathrm{a}} \pm 0.10$ & $0.57^{\mathrm{ab}} \pm 0.08$ & $0.62^{\mathrm{a}} \pm 0.09$ & $0.50^{\mathrm{b}} \pm 0.07$ \\
\hline
\end{tabular}

$\mathrm{C}=$ control; $\mathrm{CC}=$ constipated control; $\mathrm{PBY}=\mathrm{PBY}$ diet, animals not constipated; $\mathrm{PBYC}=\mathrm{PBY}$ diet, animals constipated. weight gain $=$ Average values \pm standard deviation. $\mathrm{n}=8$. Significance $(\mathrm{p}<0.05)$. Average followed by the same lower case letter in the line for each variable does not differ between each other by Tukey test. Weight gain $=($ final weight - initial weight $) ; \mathrm{CEA}=($ weight gain/total food consumption); relative weight of the caecum $=($ caecal weight $/$ weight of the animal $)$.

Table 4. Microbial groups count in total faeces and in caecal content of Wistar rats $\left(\log _{10} \mathrm{UFC} / \mathrm{g}^{-1}\right)$ from different treatments.

\begin{tabular}{ccccccccccc}
\hline \multirow{2}{*}{ Group } & \multicolumn{2}{c}{ Lactobacillus } & \multicolumn{2}{c}{ Bifidobacterium } & \multicolumn{2}{c}{ Clostridium } & \multicolumn{2}{c}{ Total Anaerobics } & \multicolumn{2}{c}{ Bacteroides } \\
\cline { 2 - 9 } & FT & CCe & FT & CCe & FT & CCe & FT & CCe & FT & CCe \\
\hline C & $9.08^{\mathrm{a}}$ & $8.51^{\mathrm{a}}$ & $9.25^{\mathrm{a}}$ & $7.97^{\mathrm{a}}$ & $9.20^{\mathrm{a}}$ & $8.17^{\mathrm{a}}$ & $9.39^{\mathrm{a}}$ & $8.14^{\mathrm{a}}$ & $6.04^{\mathrm{a}}$ & $4.49^{\mathrm{a}}$ \\
CC & $8.82^{\mathrm{a}}$ & $7.84^{\mathrm{a}}$ & $9.04^{\mathrm{a}}$ & $7.11^{\mathrm{a}}$ & $8.99^{\mathrm{a}}$ & $7.63^{\mathrm{a}}$ & $9.34^{\mathrm{a}}$ & $7.93^{\mathrm{a}}$ & $5.43^{\mathrm{ab}}$ & $4.50^{\mathrm{a}}$ \\
PBY & $9.14^{\mathrm{a}}$ & $8.27^{\mathrm{a}}$ & $8.87^{\mathrm{a}}$ & $7.81^{\mathrm{a}}$ & $9.04^{\mathrm{a}}$ & $8.08^{\mathrm{a}}$ & $8.97^{\mathrm{a}}$ & $8.20^{\mathrm{a}}$ & $4.88^{\mathrm{b}}$ & $4.41^{\mathrm{a}}$ \\
PBYC & $9.36^{\mathrm{a}}$ & $8.30^{\mathrm{a}}$ & $9.23^{\mathrm{a}}$ & $8.74^{\mathrm{a}}$ & $9.11^{\mathrm{a}}$ & $8.04^{\mathrm{a}}$ & $9.30^{\mathrm{a}}$ & $8.04^{\mathrm{a}}$ & $5.85^{\mathrm{ab}}$ & $4.69^{\mathrm{a}}$ \\
\hline
\end{tabular}

$\mathrm{C}=$ control (normal diet, not constipated); $\mathrm{CC}=$ constipated control (normal diet); PBY = PBY diet, not constipated; $\mathrm{PBYC}=\mathrm{PBY}$ diet, constipated; $\mathrm{FT}=$ total faeces; $\mathrm{CCe}=$ caecal content. $\mathrm{n}=8$. Significance $(\mathrm{p}<0.05)$; average followed by the same lower case letter in the column do not differ from others according to Tukey test.

Table 5. Height, width and depth $[\mu \mathrm{m}]$ of the crypts of the cecum of animals in different treatments after 28 days.

\begin{tabular}{|c|c|c|c|c|}
\hline \multirow{2}{*}{ Variables } & \multicolumn{4}{|c|}{ Groups } \\
\hline & $\mathrm{C}$ & $\mathrm{CC}$ & PBY & PBYC \\
\hline Height & $190.02 \pm 27.45^{\mathrm{ab}}$ & $175.03 \pm 39.47^{\mathrm{a}}$ & $172.71 \pm 32.55^{\mathrm{a}}$ & $208.85 \pm 50.86^{\mathrm{b}}$ \\
\hline Width & $37.64 \pm 9.45^{\mathrm{ab}}$ & $35.31 \pm 7.37^{\mathrm{a}}$ & $35.14 \pm 6.61^{\mathrm{a}}$ & $40.09 \pm 9.18^{\mathrm{b}}$ \\
\hline Depht & $77.91 \pm 19.45^{\mathrm{ab}}$ & $71.75 \pm 14.35^{\mathrm{a}}$ & $70.81 \pm 17.16^{\mathrm{a}}$ & $85.62 \pm 17.12^{\mathrm{b}}$ \\
\hline
\end{tabular}

$\mathrm{C}=$ control (normal diet, not constipated); $\mathrm{CC}=$ constipated control (normal diet); PBY = PBY diet, not constipated; $\mathrm{PBYC}=$ PBY diet, constipated. $\mathrm{n}=8$. Significance $(\mathrm{p}<0.05)$. Average followed by the same lower case letter in the lines does not differ between each other by Dunn's test. 
Table 6. Concentration of short chain fatty acids ( $\mathrm{mmol} / \mathrm{l})$ in Wistar rats after different treatments.

\begin{tabular}{ccccc}
\hline SCFA & C & CC & PBY & PBYC \\
\hline Acetate & $299.6 \pm 121.2^{\mathrm{a}}$ & $159.1 \pm 87.8^{\mathrm{a}}$ & $260.1 \pm 192.3^{\mathrm{a}}$ & $126.8 \pm 69.7^{\mathrm{a}}$ \\
Butyrate & $47.1 \pm 34.6^{\mathrm{a}}$ & $13.4 \pm 10.8^{\mathrm{a}}$ & $93.2 \pm 65.5^{\mathrm{b}}$ & $62.5 \pm 38.1^{\mathrm{ab}}$ \\
Propionate & $63.8 \pm 45.2^{\mathrm{a}}$ & $23.1 \pm 13.3^{\mathrm{a}}$ & $71.8 \pm 65.8^{\mathrm{a}}$ & $25.1 \pm 10.9^{\mathrm{a}}$ \\
\hline
\end{tabular}

$\mathrm{C}=$ control, not constipated $\mathrm{CC}=$ constipated control; $\mathrm{PBY}=\mathrm{PBY}$ diet, not constipated; $\mathrm{PBYC}=\mathrm{PBY}$ diet, constipated. $n=8$. Significance $(\mathrm{p}<0.05)$. Average followed by different letters in line differs significantly by Dunn's test.

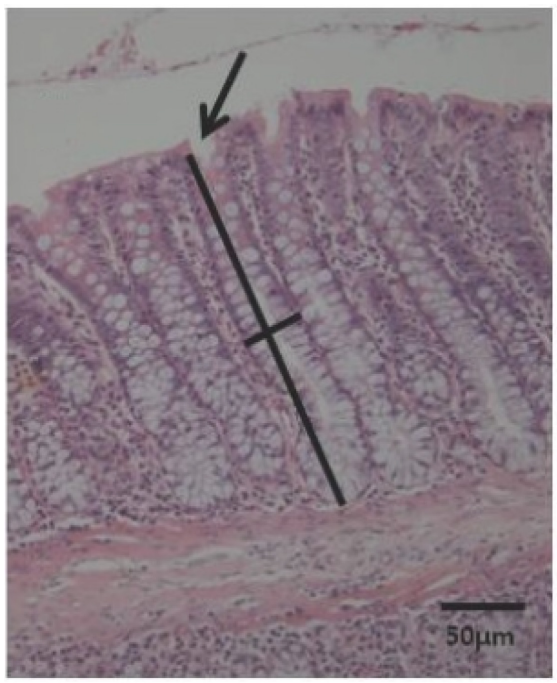

(a)

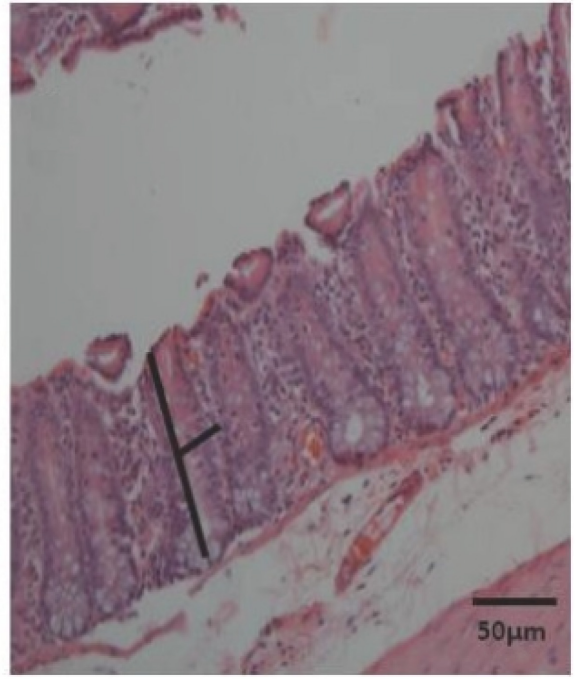

(b)

Figure 2. Histological section of the groups of the rats PBYC (a) and CC (b). Enlargement $10 \times$.

$(\mathrm{p}<0.05)$

\section{Discussion}

Constipation is a functional gastrointestinal disorder affecting the general population in all stages of life. It is increasing around the world and has been considered a chronic condition of the modern world [24] [25] [26]. Besides, because it is a condition very frequently characterized by a microbial dysbiosis and thus, leading to more severe diseases; it must be avoided/treated to ensure health betterment. Considering this, it is important the search for new tested natural functional products able to decrease risk and or treat this condition. The yacon based product (PBY), a rich source of the prebiotic FOS/inulin was herein evaluated for modulation of the induced constipation, in a murine model. Loperamide was used as inducer of constipation. This compound is a model inducer of the condition through the mechanism of inhibiting water secretion and peristalsis [37]. The condition was successfully achieved through evaluation of the animal's faecal scores. Thus, faecal score was determined in order to evaluate: 1) the induction of constipation with loperamide and 2) the PBY effect in modulating such 
constipation.

The reduced amount of faeces in the format of hard dehydrated pellets/ hard, dry pellets scoring 1 and 2, respectively, confirmed the constipation of the animals before treatment (Phase I, induction). The intervention with PBY was efficient in reducing and or eliminating the condition and confirmed with the scores averaged 3/4 of the treated animals (PBYC) after 28 day intervention (Phase II, intervention). In this group, none of the animals were scored 1 (Table 1 and Table 2).

No difference was found on the weight, feed intake or feed efficiency ratio of animals belonging to the different groups studied $(P>0.05)$. Similar study with rats [38] indicated that a diet supplemented with FOS did not affect body weight and food intake of the animals. Water retention capacity refers to the ability to retain water in the food matrix and fibers from fruits and vegetables tend to bind more water than cereal fibers. It is known that dietary components with a large water retention capacity would have an effect on the generation of faeces volume [2]. Indeed, because inulin and fructooligosaccharide molecules are soluble in water and rich in hydroxyl groups, they exert an osmotic action seen in a laxative effect observed when high doses are ingested [10]. The laxative effect of fructan prebiotics was demonstrated in a study with eight subjects under a diet containing $15 \mathrm{~g}$ of oligofructose for 45 days. This ingested, amount significantly increased the average fecal weight (136 g -154 g) of the group [10]. In the present study, $100 \%$ of the PBY treated subjects presented total fecal scores of 3 or 4 (dry, well formed and humid faeces, respectively) while 7 out of 8 (87.50\%) of the animals from the constipated group receiving the prebiotic (PBYC) were maintained in a similar range of the untreated group (PBY) (Table 2), emphasizing the functional effect of the prebiotic in decreasing the modulation of the constipation.

It is worth mention that the abnormal condition of constipation, generally correlates to microbial dysbiosis. Different microbial counts were evaluated in total faeces and in caecal content (Table 4). Shortly after the induction of constipation, there was no significant difference between the counts of the microbial groups of constipated and non-constipated animals (data not shown). At 28 days of treatment (phase II), it was found a significant lower count $(\mathrm{p}<0.05)$ for Bacteroides spp in total faeces from the PBY group when compared to the control (C) (Table 4). Bacteroides is generally considered an opportunistic genus involved in a great number of intestinal diseases. The presence of this genus has been used as a marker of bacterial dysbiosis once it includes a great number of undesirable species. In this context, the lower counts in the PBY group indicates that the prebiotic might have exerted antagonism towards Bacteroides spp., probably by selectively stimulating microorganisms whose metabolites were able to antagonize selected species of the genus. [39] [40]. Considering that some species, such as Bacteroides thetayotaomicron have important role in the intestinal eubiosis and the lack of identification at species level in this work, it is only 
possible to suggest the reasons for the observed results without drawing definitive conclusions Thus, we suggest the use molecular tools in further studies in order to verify the relative abundance of the different species present in the different treatments. The counts of Lactobacillus and Bifidobacterium, albeit similar, were high in all treatments $\left(>\log _{10} 8 \mathrm{~g}^{-1}\right)$. The presence of these genera have shown beneficial effect in constipated patients confirming one or more of the three mechanisms as described by Zhao \& Yu, 2016 (5): 1) modification of the altered microbiota of constipated individuals, 2) regulation of the intra luminal environment with metabolic end products, 3) alteration of bowel motility as result of the presence of the microbial end products. In the present study, there was no significant difference $(P>0.05)$ in the counts of the different microbial groups studied. Montesi et al. [40] found an increase in the bifidobacteria population, but not in lactobacilli in the caecum of the animals supplemented with 5.7\% FOS, and a decrease in the Bacteroides and Clostridium population. Populations within the same range have been found in other studies [41] [42] [43]. In a Spanish study [41] with non constipated Wistar rats that received 2g FOS/day, the authors detected $\mathrm{pH}$ values significantly lower than that of the control group, as well as a significant increase in the populations of Lactobacillus and Bifidobacterium in the caeca of animals treated with FOS. This increase was previously described in studies both in vitro and in vivo [42] [43] evaluating different fructans. These two bacterial groups belong to the group of lactic acid producing bacteria (LAB), capable of acidifying the environment, which inhibits the growth of pathogens [41]. In another study [44] it was detected an increase of the bifidobacteria population in the animals supplemented with FOS (60 g/kg diet) but followed by decrease in the Clostridium count, when considering the control group.

The colon carries high microbial diversity in a complex environment and the ability of microbial strains to compete and thrive for substrate fermentation is crucial in determining their dominance over other populations. Bifidobacteria are a classic example of this ability to grow and to increase in numbers when a prebiotic becomes available as a substrate for fermentation [12] [45] [46]. In the present work, increase in lactobacilli and bifidobacteria was not detected in any group treatment $(P>0.05)$ probably because the counts were already high. Differences, however, were found in total faecal $\mathrm{pH}$ between the PBY group and control (C). Lobo et al. [12] found no difference in the values of this variable in the caecum of rats supplemented with yacon meal. The established $\mathrm{pH}$ is considered to be an indirect contribution of SCFA produced from fructan fermentation and other fermentable carbohydrates by bacteria in this segment of the intestine [47] [48].

Higher concentration of butyrate was produced by the PBY group when compared to $\mathrm{C}$ and $\mathrm{CC}$ groups $(\mathrm{P}<0.05)$. These differences were 1,9 and 7 times higher, respectively. Albeit not significant, PBYC produced 5 times more butyrate than the constipated control (CC). The butyrate findings in this work 
validated the hypothesis that the prebiotic from PBY contributes to butyric acid production and purportedly, to the colon protection..This organic acid might have a role in the protection against constipation emphasized by the faecal scores shown by the PBYC animals (Table 2). In the same group, the caecal weight of the animals was lower $(\mathrm{P}<0.05)$ than that of the control group, not constipated (C). Similar results were detected by Hsu et al. [48] and Rodrigues [22] in rats supplemented with FOS. The protection of the PBYC group is also corroborated by the higher, width and depth of the intestinal epithelial cells (Table 5) found in the PBYC group when compared to the control (C). This result is outstanding once it shows that fructooligosaccharides were able to keep the intestinal morphology preserved in the group with induced constipation. Probably, the lower transit of food components increases the period of contact of these compounds with the epithelium of the constipated animals increasing the volume of this segment. Campbell et al. [38] also reported the same effect and suggested that this increase might have been caused by SCFA (particularly butyrate), which normalizes epithelial cell proliferation. Colonocytes renovation depends on the SCFA derived from bacterial fermentation, and butyrate is responsible for providing more than $70 \%$ of the oxygen consumed by human colonic tissue. In a study by Scheppach et al. (1992) [49] human colonic biopsies were exposed to butyrate ex vivo for $4 \mathrm{~h}$. It was revealed that butyrate increased the proliferation rate at $60 \%$ of the basal area of the crypt. From the current study, data from Table 5 and Table 6 show that there is an increased production of butyrate in the groups supplemented with FOS, thus causing this trophic effect on the villi. The increase in the caecum weight may also be attributed to the bacterial mass increase caused by the ingestion of the different fructans, since most bacterial fermentation in rats occur in this region [39] [50].

The rate and amount of organic acids in the colon depends on several factors, such as the type of substrate for fermentation, microbiota composition, rate of absorption and intestinal transit time [44]. Butyrate is mainly carried out by bacteria of the Clostridium spp. genus [10]. Results shown in Table 4, indicate that the population of this genus did not differ significantly from the control not constipated (C). The high population of Clostridium spp., Bifidobacterium spp. and Bacteroides spp might be associated with the high concentration of butyric acid production in the PBYC when CC not receiving PBY (Table 6), where in the former the concentration was five times that produced in the latter group. In a study of inulin supplementation at a dose of $50 \mathrm{~g} / \mathrm{kg}$ of body weight [44] higher concentrations of butyrate, acetate and propionate were found in a 14 day intervention. The authors reported that this increase was due to a large number of micro-producers of these acids, such as Clostridium perfringens and Bacteroides spp.

Butyrate is known to exert a trophic effect on the intestinal cells and it has been proved that SCFAs have a direct stimulation upon smooth muscles of ileum and colon Barbara et al., 2005 (9). The authors indicated three mechanisms by which bacteria might be involved in bowel motility: 1) intestinal neu- 
roendocrine factors, 2) mediators released by gut response and 3) fermentation bacterial end products. This third factor is represented by lactic acid and SCFAs, namely acetic, propionic and butytic acid. An adequate production of butyric acid stimulates wall thickness, generating a higher epithelial blood flow within the region, hence increasing intestinal motility [27]. Besides, butyric acid is preferentially used by colonic epithelial cells as source of energy in the process to renew the colonocytes. For this reason this organic acid is considered a main protector for colonic disorders.

A recent work stated that diet has the ability to alter the genetic composition and activity of the human enteric microbioma [51]. The diet induces changes to microorganism communities and hence, depending on the diet, the microbiome might maintain the individual in a state of health (eubiosis) or disease (dysbiosis). Thus, the increase in information on the effects of defined food/ingredient compounds upon the intestinal microbiota is of utmost importance in order to define staple foods/ingredients capable to modulate beneficially our microbiome in order to maintain the health and well being. PBY is a natural product high in FOS/Inulin, able to exert beneficial changes to gut associated microbial communities. In this study the animals with induced constipation were treated for 28 days with the diet containing FOS/Inulin. The direct observation of the faeces of the experimental animals indicated that a beneficial change in the intestinal environment occurred, since the PBY subjects received faecal scores similar to the control (C) animals The similar levels in ceacal $\mathrm{pH}$ and the lack in difference among the different treatments indicates that it is an area of high stability. The $\mathrm{pH}$ of the total faeces from PBYC did not differ from the control, not constipated group (C) suggesting a possible maintenance of a beneficial microbiota able to protect the intestinal colonocytes and thereby protecting the intestinal ephytelium from the damages of constipation.

\section{Conclusion}

This study presented an effect of PBY, a yacon (Smallanthus sonchifolius) based product, on modulating positively constipation in rats by changing faecal score and increasing faecal moisture of the treated animals. PBY promoted a higher production of butyrate, decreased Bacteroides spp counts, and increased width, height and crypt depth in caecum of the animals treated with the product. Despite the proven benefits, further studies are necessary to define the relation between the physiological changes observed and the intestinal microbiome, in order to outline mechanistically the traits involved in the observed benefits. Furthermore, before the clearing of the product for human consumption, there is a need for well conducted human trials.

\section{Acknowledgements}

The study was supported by the National Council of Scientific and Technological Development-CNPq and the Foundation for Research Support of the State 
of Minas Gerais-FAPEMIG.

\section{Conflicts of Interest}

The authors declare no conflicts of interest regarding the publication of this paper.

\section{References}

[1] Roberfroid, M.B. (2002) Functional Food Concept and Its Application to Prebiotics. Digest Liver Disease, 34, S105-S110. https://doi.org/10.1016/S1590-8658(02)80176-1

[2] Roberfroid, M.B. (2007) Inulin-Type Fructans: Functional Food Ingredients. Journal of Nutrition, 137, 2493S-2502S. https://doi.org/10.1093/jn/137.11.2493S

[3] Waitzberg, D.L., Logullo, L.C., Bittencourt, A.F., Torrinhas, R.S., Shirom, G.M., Paulino, N.P., et al. (2013) Effect of Synbiotic in Constipated Adult Women: A Randomized, Double-Blind, Placebo-Controlled Study of Clinical Response. Clinical Nutrition, 32, 27-33. https://doi.org/10.1016/j.clnu.2012.08.010

[4] Louis, P., Scott, K.P., Duncan, S.H. and Flint, H.J. (2007) Understanding the Effects of Diet on Bacterial Metabolism in the Large Intestine. Journal of Applied Microbiology, 102, 1197-1208. https://doi.org/10.1111/j.1365-2672.2007.03322.X

[5] Zhao, Y. and Yu, Y. (2016) Intestinal Microbiota and Chronic Constipation. Springer Plus, 5, 1130. https://doi.org/10.1186/s40064-016-2821-1

https://www.ncbi.nlm.nih.gov/pmc/articles/PMC4951383/pdf/40064_2016_Article_ 2821.pdf

[6] Manhart, N., Spittler, A., Bergmeister, H., Mittlbock, M. and Roth, E. (2003) Influence of Fructooligosaccharides on Peyer's Patch Lymphocyte Numbers in Healthy and Endotoxemic Mice. Nutrition, 19, 657-660. https://doi.org/10.1016/S0899-9007(03)00059-5

[7] Scholz-Ahrens, K.E., Ade, P., Marten, B., Weber, P., Timm, W., Asil, Y., Gluer, C.C. and Schrezenmeir, J. (2007) Prebiotics, Probiotics, and Synbiotics Affect Mineral Absorption, Bone Mineral Content, and Bone Structure. Journal of Nutrition, 137, 838S-846S. https://doi.org/10.1093/jn/137.3.838S

[8] Cherbut, C., Michel, C. and Lecannu, G. (2004) The Prebiotic Characteristics of Fructooligosaccharides Are Necessary Forreduction of TNBS-Induced Colitis in Rats. The Journal of Nutrition, 133, 21-27. https://doi.org/10.1093/jn/133.1.21

[9] Barbara, G., Stanghellini, V., Brandi, G., Cremon, C., Di Nardo, G., De Giorgio, R., et al. (2005) Interactions between Commensal Bacteria and Gut Sensorimotor Function in Health and Disease. American Journal of Gastroenterology, 100, 2560-2568. https://doi.org/10.1111/j.1572-0241.2005.00230.x

[10] Gibson, G. and Roberfroid, M. (1995) Dietary Modulation of the Human Colonic Microbiota Introducing the Concept of Prebiotics. Journal of Nutrition, 125, 1401-1412.10.

[11] Gibson, G.R., Hutkins, R., Sanders, M.E., Prescott, S.L., Remmer, R.A., Salminen, S.J., Scott, K., Stanton, C., Swanson, K.S., Cami, P.D., Verbeke, K. and Reid, G. (2017) The International Scientific Association for Probiotics and Prebiotics (ISAPP) Consensus Statement on the Definition and Scope of Prebiotics. Expert Consensus Document. Nature Ver./Gastroenterol \& Hepatol., 14, 491-502.

https://doi.org/10.1038/nrgastro.2017.75

https://www.nature.com/articles/nrgastro.2017.75.pdf

[12] Lobo, A., Colli, C., Eliana, P. and Tullia, M. (2007) Effects of Fructans Containing Yacon [Smallanthus sonchifolius Poepp \& Endl.] Flour on Caecum Mucosal Mor- 
phometry, Calcium and Magnesium Balance, and Bone Calcium Retention in Growing Rats. Britsh Journal of Nutrition, 97, 776-785. https://doi.org/10.1017/S0007114507336805

[13] Passos, L.M.L. and Park, Y.K. (2003) Frutooligossacarídeos: Implicações na saúde humana e utilização em alimentos. Ciência Rural, 33, 385-390. https://doi.org/10.1590/S0103-84782003000200034

[14] Fortes, R.C. and Muniz, L.B. (2009) Efeitos da suplementação dietética com frutooligossacarídeos e inulina no organismo humano: Estudo baseado em evidências. Comunicação em Ciências da Saúde, 20, 241-252.

[15] Aybar, M., Sanchez-Riera, A., Grau, A. and Sanchez, S. (2001) Hypoglycemic Effect of the Water Extracts of Smallantus sonchifolius [yacon] Leaves in Normal and Diabetic Rats. Journal of Ethnopharmacology, 74, 125-132.

https://doi.org/10.1016/S0378-8741(00)00351-2

[16] Graefe, S., Hermann, M., Manrique, I., Golombek, S. and Buerkert, A. (2004) Effects of Post-Harvest Treatments on the Carbohydrate Composition of Yacon Roots in the Peruvian Andes. Field Crops Research, 86, 157-165.

https://doi.org/10.1016/j.fcr.2003.08.003

[17] Vilhena, S.M.C., Camara, F.L.A. and Kakihara, S.T. (2000) O cultivo de yacon no Brasil. Horticultura Brasileira, 18, 5-8. https://doi.org/10.1590/S0102-05362000000100002

[18] Lachman, J., Fernandez, E.C. and Orsak, M. (2003) Yacon [Smallanthus sonchifolia (Poepp. et Endl.) H. Robinson] Chemical Composition and Use-A Review. Plant, Soil and Environment, 49, 283-290. https://doi.org/10.17221/4126-PSE

[19] Genta, S., Cabrera, W., Habib, N., Pons, J., Carillo, I.M., Grau, A. and Sánchez, S. (2009) Yacon Syrup: Beneficial Effects on Obesity and Insulin Resistance in $\mathrm{Hu}-$ mans. Clinical Nutrition, 28, 182-187. https://doi.org/10.1016/j.clnu.2009.01.013

[20] Rodrigues, V.C. (2011) Formulação, índice glicêmico e aplicação alimentar de um produto à base de yacon [Smallanthus sonchifolius]. Tesis, $89 \mathrm{p}$.

[21] Scheid, M.M.A., Genaro, O.S., Moreno, Y.M.F. and Pastore, G.M. (2014) Freeze Dried Powdered Yacon: Effects of FOS on Serum Glucose, Lipids and Intestinal Transit in the Elderly. European Journal of Nutrition, 53, 1457-1464. https://doi.org/10.1007/s00394-013-0648-x

[22] Moura, N.A., Caetano, B.F.R., Sivieri, K., Urbano, L.H., Cabello, C., Rodrigues, M.A.M. and Barbisan, L.F. (2012) Protective Effects of Yacon (Smallanthus sonchifolius) Intake on Experimental Colon Carcinogenesis. Food and Chemical Toxicology, 50, 2902-2910. https://doi.org/10.1016/j.fct.2012.05.006

[23] Geyer, M., Manrique, I., Degen, L. and Beglinger, C. (2008) Effect of Yacon [Smallanthus sonchifolius] on Colonic Transit Time in Healthy Volunteers. Digestion, 78, 30-33. https://doi.org/10.1159/000155214

[24] Pare, P., Ferrazzi, S., Thompson, W.G., Irvine, E.J. and Rance, L. (2001) An Epidemiological Survey of Constipation in Canada: Definitions, Rates, Demographics, and Predictors of Health Care Seeking. The American Journal of Gastroenterology, 96, 3130-3137. https://doi.org/10.1111/j.1572-0241.2001.05259.x

[25] Higgins, P.D. and Johanson, J.F. (2004) Epidemiology of Constipation in North America: A Systematic Review. The American Journal of Gastroenterology, 99, 750-759. https://doi.org/10.1111/j.1572-0241.2004.04114.x

[26] Sant'Anna, M.S.L., Coelho, C.G. and Ferreira, C.L.L.F. (2012) Prevalência de constipação intestinal no município de Viçosa-MG. 10th Congresso Brasileiro de 
Saúde Coletiva, Porto Alegre, 14 November 2012, 134-135.

[27] Kaur, N. and Gupta, A.K. (2002) Applications of Inulin and Oligofructose in Health and Nutrition. Journal of Biosciences, 27, 703-714.

https://doi.org/10.1007/BF02708379

[28] Bielecka, M., Biedrzycka, E., Majkowska, A., Juskiewicz, J. and Wróblewska, M. (2002) Effect of Non-Digestible Oligosaccharides on Gut Microecosystem in Rats. Food Research International, 35, 139-144. https://doi.org/10.1016/S0963-9969(01)00175-2

[29] Association of Official Analytical Chemists (1997) Official Methods of Analysis of the AOAC. 12th Edition, Washington DC. https://doi.org/10.11606/D.10.2003.tde-31052004-092206

[30] Shimotoyodome, A., Meguro, S., Hase, T., Tokimitsu, I. and Sakata, T. (2000) Decreased Colonic Mucus in Rats with Loperamide-Induced Constipation. Comparative Biochemistry and Physiology, 126, 203-221. https://doi.org/10.1016/S1095-6433(00)00194-X

[31] Veronesi, C. (2003) Efeito de dois alimentos comerciais secos no consumo energético, peso vivo e peso metabólico, escore corporal, escore e peso fecal de cães adultos em manutenção e atividade. 93f. Dissertação, USP.

[32] Rogosa, M., Mitchell, J.A. and Wiseman, R.F. (1951) A Selective Medium for the Isolation and Enumeration of Oral and Fecal Lactobacilli. Journal of Bacteriology, 62, 132-133.

[33] Hartemink, R., Vanlaere, K.M.J. and Rombouts, F.M. (1997) Growth of Enterobacteria on Fructooligosaccharides, Wageningnen, Holanda. Journal of Applied Microbiology, 383, 367-374. https://doi.org/10.1046/j.1365-2672.1997.00239.x

[34] Santos, M.S., Ferreira, C.L.L.F., Santos, J.L., Pozza, P.C. and Teshima, E. (2003) Influência do fornecimento de probiótico à base de Lactobacillus sp. sobre a microbiota intestinal de leitões. Ciência e Agrotecnologia, 27, 1395-1400. https://doi.org/10.1590/S1413-70542003000600026

[35] Rosa, D.D., Sales, R.L., Moraes, L.F.S., Lourenço, F.C., Neves, C.A., Sabarense, C.M. and Pelúzio, M.C.G. (2010) Flaxseed, Olive and Fish Oil Influence Plasmatic Lipids, Lymphocyte Migration and Morphometry of the Intestinal of Wistar Rats. Acta Cirurgica Brasileira, 25, 275-280. https://doi.org/10.1590/S0102-86502010000300010

[36] Smirick-Ktjardes, M.R., Griedshop, C.M. and Flickinger, E.A. (2003) Dietary Galactooligosaccharides Affect Ileal and Total-Tract Nutrient Digestibility, Ileal and Fecal Bacterial Concentrations, and Ileal Fermentive Characteristics of Growing Pigs. American Society of Animal Science, 81, 2535-2545.

[37] Takasaki, K., Kishibayashi, N., Ishii, A. and Kaarasawa, A. (1994) Effects of KW-5092, a Novel Gastroprokinetic Agent, on the Delayed Colonic Propulsion in Rats. The Japanese Journal of Pharmacology, 65, 67-71. https://www.ncbi.nlm.nih.gov/pubmed/8089932

[38] Campbell, J.M., Fahey, G.C. and Wolf, B.W. (1997) Selected Indigestible Oligosaccharides Affect Large Bowel Mass, Cecal and Fecal Short-Chain Fatty Acids, ph and Microflora in Rats. Journal of Nutrition, 127, 130-136. https://doi.org/10.1093/jn/127.1.130

[39] Lucke, K., Miehlke, S., Jacobs, E. and Schuppler, M. (2006) Prevalence of Bacteroides and Prevotella spp. in Ulcerative Colitis. Journal of Medical Microbiology, 55, 617-624. https://doi.org/10.1099/jmm.0.46198-0

[40] Montesi, A., Garcia-Albiach, R., Pozuelo, M.J., Pintado, C., Goni, I. and Rotger, R. 
(2005) Molecular and Microbiological Analysis of Caecal Microbiota in Rats Fed with Diets Supplemented Either with Prebiotics or Probiotics. International Journal of Food Microbiology, 98, 281-289.

https://doi.org/10.1016/j.ijfoodmicro.2004.06.005

[41] Rodriguez-Cabezas, M.E., Camuesco, D., Arribas, B., Garrido-Mesa, N., Comalada, M., Bailón, E., et al. (2010) The Combination of Fructooligosaccharides and Resistant Starch Shows Prebiotic Additive Effects in Rats. Clinical Nutrition, 29, 832-839. https://doi.org/10.1016/j.clnu.2010.05.005

[42] Hernot, D.C., Boileau, T.W., Bauer, L.L., Middelbos, I.S., Murphy, M.R., Swanson, K.S., et al. (2009) In Vitro Fermentation Profiles, Gas Production Rates, and Microbiota Modulation as Affected by Certain Fructans, Galactooligosaccharides, and Polydextrose. Journal of Agricultural and Food Chemistry, 57, 1354-1361. https://doi.org/10.1021/jf802484j

[43] Van de Wiele, T., Boon, N., Possemiers, S., Jacobs, H. and Verstraete, W. (2007) Inulin-Type Fructans of Longer Degree of Polymerization Exert More Pronounced in Vitro Prebiotic Effects. Journal of Applied Microbiology, 102, 452-460. https://doi.org/10.1111/j.1365-2672.2006.03084.x

[44] Hsu, C.K., Liao, J.W., Chung, Y.C., Hsieh, C.P. and Chan, Y.C. (2004) Xylooligosaccharides and Fructooligosaccharides Affect the Intestinal Microbiota and Precancerous Colonic Lesion Development in Rats. The Journal of Nutrition, 134, 1523-1528. https://doi.org/10.1093/jn/134.6.1523

[45] Rossi, M., Corradini, C., Amaretti, A., Nicolini, M., Pompei, A., Zanoni, S. and Matteuzzi, D. (2005) Fermentation Offructooligosaccharides and Inulin by Bifidobacteria: A Comparative Study of Pure and Fecal Cultures. Applied and Environmental Microbiology, 71, 6150-6158. https://doi.org/10.1128/AEM.71.10.6150-6158.2005

[46] SantÀnna, M.S.L. and Ferreira, C.L.L.F. (2014) Can Intestinal Constipation Be Modulated by Prebiotics, Probiotics and Symbiotics? Food \& Nutrition Sciences, 5, 1106-1113. https://doi.org/10.4236/fns.2014.512120

[47] Lu, Z.X., Gibson, P.R., Muir, J.G., Fielding, M. and O’Dea, K. (2000) Arabinoxylan Fiber from a By-Product of Wheat Flour Processing Behaves Physiologically like a Soluble, Fermentable Fiber in the Large Bowel of Rats. Journal of Nutrition, 130, 1984-1990. https://doi.org/10.1093/jn/130.8.1984

[48] Paturi, G., Butts, C.A., Stoklosinski, H. and Ansell, J. (2012) Effects of Early Dietary Intervention with a Fermentable Fibre on Colonic Microbiota Activity and Mucin Gene Expression in Newly Weaned Rats. Journal of Functional Foods, 4, 520-530. https://doi.org/10.1016/j.jff.2012.02.013

[49] Scheppach, W., Sommer, H., Kirchner, T., Paganelli, G.M., Bartram, P., Christl, S., et al. (1992) Effect of Butyrate Enemas on the Colonic Mucosa in Distal Ulcerative Colitis. Gastroenterology, 103, 51-56. https://doi.org/10.1016/0016-5085(92)91094-K

[50] Kleessen, B., Hartmann, L. and Blaut, M. (2014) Oligofructose and Long-Chain Inulin: Influence on the Gut Microbial Ecology of Rats Associated with a Human Faecal Flora. British Journal of Nutrition, 86, 291-300. https://doi.org/10.1038/nature12820

[51] David, L.A., et al. (2014) Diet Rapidly and Reproducibly Alters the Human Gut Microbiome. Nature, 505, 559-563. 